\title{
Evaluating Enterprize Delivery Using the TYPUS Metrics and the KILT Model
}

\section{George L. Kovács}

Computer and Automation Research Institute of the Hungarian Academy of

Sciences, Kende u. 13-17, 1111 Budapest, Hungary

University of Pécs and Technical University of Budapest

gkovacs@sztaki.hu

\begin{abstract}
The goal of this work is the technical, ecological, environmental and social examination of the life-cycle ( $L C)$ of any product (consumable, service, production) using the TYPUS metrics and the KILT model. The life-cycle starts when the idea of a product is born and lasts until complete dismissal through design, implementation and operation, etc. In the first phases requirements' specification, analysis, several design steps (global plan, detailed design, assembly design, etc.) are followed by part manufacturing, assembly, testing, diagnostics and operation, advertisement, service, maintenance, etc. Then finally disassembly and dismissal are coming, but dismissal can be substituted by re-cycling (e.g. melting the metals) or re-use (used parts applications). Qualitative and quantitative evaluations of enterprise results are supported by the new models and metrics.
\end{abstract}

Keywords: enterprise delivery; environment; life-cycle management; energy; sustainability

\section{Introduction}

The topic of this paper is the investigation of the life-cycle-management (LCM), or simply life-cycle (LC) of any product (parts, assemblies, services, production units, consumables, etc.) for the total life-cycle. Life-cycle starts when the idea of a product (service, etc.) is born and lasts until the disposal (or reuse, recycling) of the given item. In the first phases there are the requirements' gathering, analyzes, planning (global plans, detailed plans, assembly plans, etc.), then comes parts' manufacturing (including assembly), testing, diagnostics, and the manufacturing is done. Control, service, advertisement and sales are parts of the LCM, as well as maintenance and repair, etc. Finally when the product is worn out or becomes useless there is the destruction (disposal) or reuse (e.g. disassembly of used, but useful parts) or recycling (e.g. melting again). These processes are often modeled and simulated with different models and simulators depending on designer, user, manufacturer, operator, and depending on the complexity of the product. Reuse and recycling were not taken seriously for a long time, now they are understood 
more and more widely - due to the real or expected energy-, material- and watershortage in the near and remote future. Even working-force shortage can be imagined in spite of the recently high (more than 10\% in Hungary in 2012) unemployment rate in the developed countries.

We plan to investigate the ecological footprint (environmental effects, energy- and material- consumption, $\mathrm{CO}_{2}$ emission, etc. of manufacturing and usage (operation) of different products and services. The detailed study of these issues and the evaluation of international literature and of measures' of governments and public bodies can be found in [2] and [3], in the books of Prof. Michelini.

A note: in November, 2010 a plenary lecturer at the Hungarian Academy of Sciences at the "Day of Science" stated the following: "A cup of coffee needs the consumption of 600 liter water if everything is taken into account". It means everything from watering the plants to washing the dishes, etc. Another interesting issue can be the electric (or hybrid) car, if all effects of battery acid and heavy metals, etc. are taken into account from mining to dangerous crap.

The KILT model and TYPUS metrics will be explained and used for our study, for details see [1], [2] and [3].

The main goal of our study is to model and quantify the complete delivery (all products, side-products, trash and effects of them, i.e. all results), and changes of the delivery of a firm, and to model all interesting and relevant steps of the LC (or LCM).

In connection with the already well known 'extended enterprises' and 'sustainable development' some notions and their relationships are worth to take a look without going into details - for the LCM point of view:

- To use extended product - defined based on the philosophy of the extended enterprise

- To distinguish between the product itself and the services provided by the given product

- To distinguish between the tangible and intangible (non-material) aspects of a product

- Fig. 1 needs some explanation. It is a rather simplified view of some main players in the production/service arena, however it still shows quite well certain main qualitative relationships among the given players. We believe that these can be used to understand what is going on in our (engineeringmanufacturing-sustainable) world. The TYPUS/KILT metrics, methodology and model give us possibility to better understand and evaluate production results and their components in terms of the defined K, I, L, T notions and values. They give us a method of calculations and comparisons based on realistic values, and not only qualitative, but quantitative evaluations can be done, too. The side effects and $2^{\text {nd }}$ and $3^{\text {rd }}$ order effects, etc. mean the following, explained using a simple and simplified example instead of a precise definition: let us consider the production of a hybrid car. 


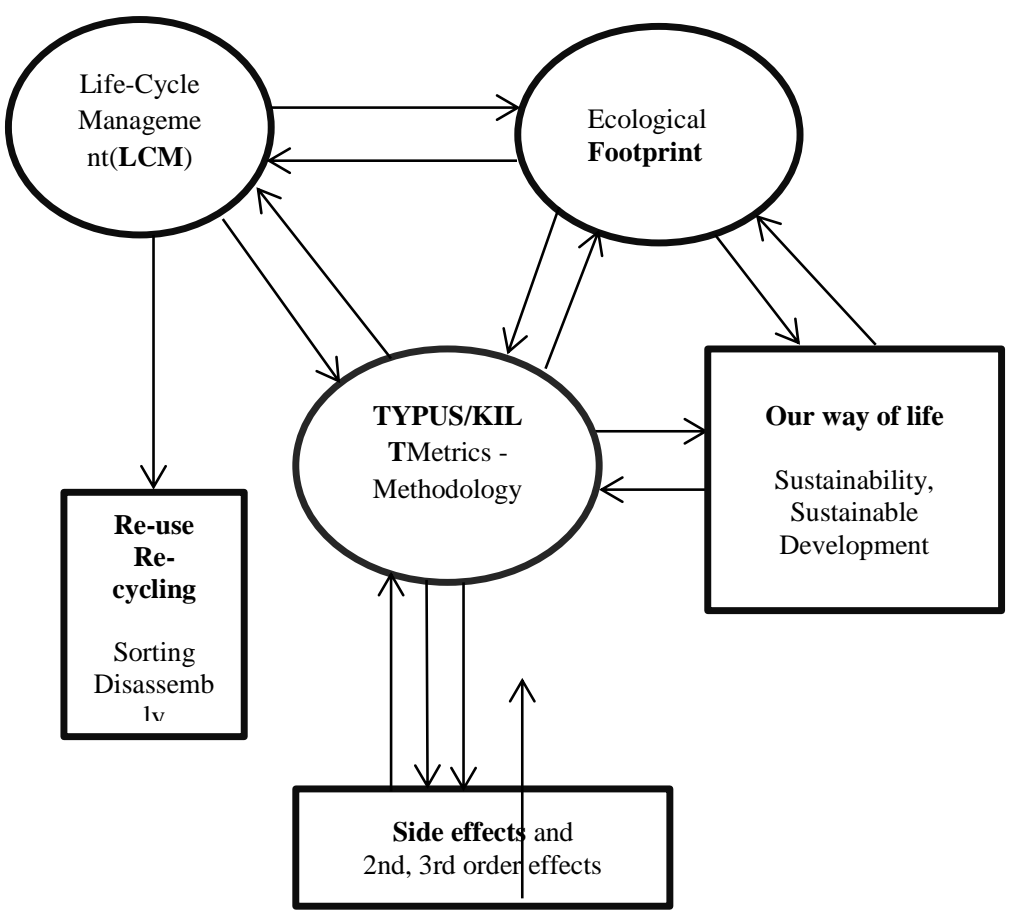

Figure 1

Some basic LCM-footprint-KILT relationships

It means (today) (among others) to produce and build in two engines, two engines need more metal than one (side effect), to produce more metal we need more electrical energy and more ores ( $2^{\text {nd }}$ order side effect), to produce more electricity more fuel is necessary and to produce more ores needs more miners' work ( $^{\text {rd }}$ order side effect), etc., and it could be continued. It is a hard task to know how deep and how broad we should go with such calculations. And if we take a look at our example there are several other viewpoints (breadth increase) that could be taken into account. Just one example: the increased water consumption during mining. The other blocks of Fig. 1 are closed to trivial, there is no problem with understanding and interpretation.

Our future results will help to examine not only working, operating enterprises (all defined as products), but even enterprises under design can be evaluated taking into account several environmental, ecological, human and other issues of sustainable development or simply of sustainability. This way life-cycle engineering (LCE), or simply LC design can be supported, too. The whole system can be used as a kind of simulation; it gives assistance to imagine something that will work in the future only. To properly understand the need of measurement and evaluation of enterprise results (delivery, all output) in every phase of the LC it is necessary to analyze products and production in details from several viewpoints, including environment effects. This will be done in Chapter 2. 
Today, the 'ecologism' discovers the damages of the industrial economy, greatly based on the manufacture transformation efficiency, making withdrawals from finite earth stocks, and piling up waste and pollution amounts, exceeding the natural recovery potentiality. Hence, natural opposes to artificial, in view to limit dumping and contamination, moving back the growth rate at pre-industry figures. In the anthropic vision (relating to human beings or the period of their existence on earth), the nature never opposes to the human, being, in reality, only helpful complement of the progress. Some other visions had different nature in the past and even today. However, the term "natural capital" is a recent designation, openly linked to the ecology movements.

The designation is notably effective, when the accounting schemes are requested. As an example, let us take "materials". The production of everything necessitates materials, compulsorily to be taken from somewhere. The processes require appropriate monitoring. The balances split up to the renewable and the nonrenewable resources. The latter shall be classified in terms of (direct, instrumental, etc.) usefulness, (express, subsequent, etc.) toxicity, (local, global, etc.) rarity, and so on, assuming the unidirectional flow from provisioning, to useful products. The point-of-sale denotes the manufacturer's interest end, leaving entire responsibility of the use, misuse and disposal to the purchasers. These irresponsible supply chains are made legal by the current bylaws, to be, in reality, better classified as populism superficiality or swindle.

The description is coherent with the economic productivity, specified in the manufacturing phase, and exploiting the instant supply/demand balance in the materials' provision, with no worry for the context. The tax systems follow similar logics: e.g., the VAT moves along the supply chain, charging the increments, utterly neglecting the correlated spoil amounts and effluence levels. This method is faulty: the earth stocks will run out; the environment will turn lethal; only, the today consumers (producers and buyers) make profit.

\section{Products, Progress, Life-cycle, Energy, Environment}

The already outlined remarks require revising the current attitude about the supply chains. The following - really different, but corresponding - points (levels and ranks) are hereafter could be recalled:

- at the agricultural products' level: aspects in the farm and breeding activity, based on iterating controlled biological cycles

- at the industrial products' level: facets in the manufacture doing, grounded on better consciousness of the decline threats 
- $\quad$ at the business stability rank: the model for the evaluation of all (four) capital assets (K, I, L, T), involved in the shop-floor processes

- $\quad$ at the lawfulness rank: the (example) metrics for the tangibles' appraisal, by standard (legal metrology) bookkeeping.

The above four points stress world-wide examined concepts: the need to give autonomy to the "natural capital", in view that the visibility might motivate enhanced eco-consciousness; the manufacturers' responsibility on the product lifecycle, leaving aside the misleading restriction on the consumers. Both concepts are, perhaps, obvious, but are late in the awareness of many current operators, which prefer naive (actually, egoistic) simplifying assumptions, not to give visibility to the ecology cycle. On these points, more virtuous supply chains are deemed to establish, aiming at better balancing the available resources, not to permit the hoardings and lootings of confident profiteers.

\subsection{The Agricultural Products}

These were perhaps the first "products" in the history of mankind. The man controlled biological cycles are archaic ideas, discovered in the pre-history times. The domestication of animals and vegetable species is a surprising success of the group selection, leading to the farming communities, leaving behind the starvation risks of the pickers/hunters' assemblies. The human intervention on the earth surface has been, up to now, so invasive, to make hopeless understanding the today earth surroundings are subject to merely spontaneous (with no artificial human action) changes of the evolutionism. We do not discuss this important issue in the recent study in details, as it is out of our scope today.

\subsection{History Outlook and Progress in Industry}

The man controlled industrial cycles are recent, first fulfilled in some earth regions. The industrial revolution is considered to be typical outcome of the capitalism, especially promoted by the nation-state combined backing of the venture companies, which are entitled to pursue public and private profits. The widespread exploitation of artificial energy is a primary technological innovation; the work-organization efficiency is a fundamental enabling complement. The two facts alone do not show radical divides. The typical effects of the steam power were already acknowledged. The job allotment rules were known practice in the arsenals ship-building. The revolution is a shared issue of enterprises immersed in the new specific cultural surroundings of a subset of populations.

The industrial revolution, as a recent achievement, has throughout descriptions, making possible to assess early developments and cross-links more sharply than for the agricultural revolution. The "industry" is defined as the business establishment, which nicely exploits the structured work-organization and the 
facility-integration. The meaning is, either: branch of trade or manufacture, assuring productive efficiency; or: diligence and habitual employment in useful activities (industrious is equal to diligent).

The industrial revolution has motivated altering the meaning of several things. The process is somehow mirror of the one pursued by the word "culture", from the land cultivation, to the people instruction. In its original form, the industry has been based on the scientific work-organization and the economy of scale through the mass-production. The recent robot technologies have brought out the intelligent work-organization and the economy of scope through one-of-a-kind manufacture. The industry patterns undergo changes; the variations amplify the opportunities, as it was the case, with the agricultural revolution.

The industrialism has promoted the affluent society and consumerism. The drawbacks are well assessed; they open impending threats to the earth progress. The manufacture process concerns non-renewable resources. As well, the irreversible transformations deteriorate the surroundings, with damages to the biosphere. The changes towards the intelligent work-organization depend on the integration of computer engineering tools. These have already been recognized as key help "to de-materialize", and relevant support for the "natural capital" bookkeeping.

As soon as the negative aspects of the industrialism are made clear, the search for remedies shall start. The total suppression of the material goods is a non-sense. The burning up of inanimate stuffs is standard process to carry on the vital cycles. The resort to artificial energy highly (and selectively) speeds up the consumption rates, but again, the simple suppression of the option is meaningless, not to wipe out the current quality of life. The possible remedies are, quite sadly, only partial and temporary:

- to augment the tangibles' productivity, obtaining larger output, while lowering the native exploited input (process effectiveness and recovery/ reclamation closure);

- to discover suited "to re-materialize" cycles, renewing the amount of useful earth stocks, at artificial rates ("robot age" technology transformations).

The success of remedies will not aim at unlimited progress, rather at bounded growth, consistent with the weak anthropic bio-sphere's duration forecasts. The current engineering concerns are analyses on how to improve the resource effectiveness. They include a mix of opportunities, such as the following, for example:

- $\quad$ to reinvent the manufacture cycles, under resource manager liability;

- to avoid waste, planning closed flows, chaining outputs into inputs

- $\quad$ to deliver functions, replacing goods, under unified overseeing; 
- to invent domotics (home automation), optimizing the energy controlled delivery

- $\quad$ to supply lifecycle service, fulfilling maintenance and refurbishing

- to perform reverse logistics, up to mandatory recovery targets

The example list show already well understood businesses, which are deemed expanding in the near future. The "to re-materialize" remedy is a longer term issue, involving, most likely, the agricultural ideas, to deal with animated resources, and to exploit suitable bio-mimicry transformations, which enable the related self-reproduction capacities. Now it is impossible to abolish the industrial products, as in the past, these did not remove the land produces. The remedies aim at finding out conservative tracks and replacement means, according to suitably planned restoring/remediation criteria.

The doable remedies have an extraordinary imperative trait of urgency. The climate changes hurry up the need of lowering the contamination, starting by the $\mathrm{CO}_{2}$ emission. This comes from the oxidization processes, including the ones of animal life. The atmosphere of the earth is highly oxidizing, having the $21 \%$ of oxygen. Some 4.5 billion years ago, the atmosphere was highly reducing. The actions of photo-synthesis moved towards the today balance; without it, the $\mathrm{CO}_{2}$ would become dominant. The current composition is only marginally stable: at higher $\mathrm{O}_{2}$ concentration, self-combustion establishes (by $24 \%$ of $\mathrm{O}_{2}$ ). Furthermore, all living beings needs energy, and mainly exploit the $2 \mathrm{H}_{2}+\mathrm{O}_{2}=>$ $2 \mathrm{H}_{2} \mathrm{O}$, highly exothermic reaction, which allows reaching to life-suited temperature.

The today atmosphere has about $0.05 \% \mathrm{CO}_{2}$ (78\% nitrogen, $1 \%$ argon). Bigger $\mathrm{CO}_{2}$ emissions have rising side falls-off (greenhouse effect, etc.), altering the biosphere equilibrium. The real dynamics depends on multiple factors. Several models are in use, to simulate potential scenarios. The control of the $\mathrm{CO}_{2}$ emission is a critical request, to preserve the rather peculiar earth habitat, having negligible $\mathrm{CO}_{2}$, in spite of the highly oxidizing atmosphere. The environment-industry will become key business in the tomorrow world, which adds to the entrepreneurial developments. The innovation is technical capital challenge.

\subsubsection{Some More Historical Energy and Environment Hints}

It is worthwhile to mention that in the childhood of the author, at the beginning of the nineteen fifties the western countries started to understand the problems of keeping our environment "green" and "clean" taking care of some natural resources (for example: "Keep America Clean !!”). However this understanding was rather partial. The first steps to solve some problems of the fast decrease of easy availability of some metals and of clear water were done, however the whole world believed that energy and fuel/gasoline supply is infinite. At least they were behaving as it were. This led to the huge cars in the USA using too much gasoline and to the huge refrigerators and air-conditioning equipment using huge amount of 
electrical energy, etc. And we, the whole world were proud of the increasing amount of used energy. Somehow similarly to the recent Moore's low in microelectronics mankind was proudly announcing the fast increase of energy consumption. Moore's law describes a long-term trend in the history of computing hardware whereby the number of transistors that can be placed inexpensively on an integrated circuit doubles approximately every two years. Relative data (increase of energy consumption in \%) of the socialist countries, led by the Soviet Union were even higher, as they started rather low.

Nature and environment were different issues in our countries. While the Western hemisphere already understood from the fifties of the $20^{\text {th }}$ Century the rules of coexistence with the environment the Eastern block was still fighting to change the natural environment and to win against nature. Even exaggerations as changing the flow directions of some rivers, irrigation of deserts for agricultural usage and introduction/deployment of several different plants and animals in areas where they never lived before - and cannot live today - were supported and resulted in catastrophic results in most cases.

In [4] we find the following: Electrical-energy production stood at 329 billion kilowatts in 1950 in the USA, 232 per cent more than the 142 billion in 1940, with the cost per kilowatt steadily declining. It means an increase of approx. 23\%/year. Most of the electrical energy was produced with power stations run be fossil fuels (natural gas, coal and crude oil). Soon after the end of World War II a vast array of new electrical devices made its way into households, including dishwashers, freezers, dryers, vacuum cleaners, ranges and ovens, and refrigerators. The availability of smaller items such as vacuum cleaners increased through door-todoor sales, and larger items were popular, too.

The next twenty-two years, between 1950 and 1972, total world energy consumption increased 179 per cent, much faster than population growth, resulting in a doubling of per capita energy consumption. This means a decrease in comparison to the previous 10 years, however still an average increase of $8 \%$ /year. Oil accounted for much of this increase, rising from 29 per cent of world energy consumption in 1950 to 46 per cent in 1972. By 1973, oil accounted for 47 per cent of U.S. energy consumption. Western Europe and Japan were even more dependent on oil for meeting their energy needs; by 1973 oil accounted for 64 per cent of west European energy consumption and 80 per cent of Japanese energy consumption. For more details see [5]. After the 1972-73 oil crisis the increase of energy consumption was a rather low value, 1\%/year only in average until 1992. Governments understood a lot and had several measures worldwide. Then from 1992 to 2000 an increased increase $(2.5 \%$ /year) meant that the fear of shortages earlier was exaggerated [6].

Today the whole world, all at least most countries understand the importance of natural resources, environment, and based on this understanding reuse and recycling are getting more and more important in everyday life, as well as the 
decrease of $\mathrm{CO}_{2}$ emission, etc. These all request to keep energy, water, natural resources, manpower, etc. consumption in a moderate, sustainable level. This leads to sustainable development, or even to sustainability.

\subsection{Business and Law Aspects}

These are extremely important but out of the recent scope, and they will not be discussed in this paper.

\section{Shop-floor Modelling - Industrial Approach}

The manufacturing/production activity cannot be suppressed, even if the transformation of raw materials based on artificial energy is a paradigmatic example of consumerism and natural capital decay. When planning for remedies, three facts ought to be taken into account:

- to recognize that the natural capital use requests refunding of all the withdrawals;

- to assess and to bill the materials' costs, with resort to fair legal metrology schemes;

- $\quad$ all factors, players, parts of the LC should be measured and evaluated for all time spans.

\subsection{The KILT Model and the TYPUS Metrics}

TYPUS metrics means Tangibles Yield per Unit of Service. It is measured in money - on ecological basis. It reflects the total energy and material consumption of (all) extended products of a given unit, e. g. of an enterprise.

The metrics assumes:

- to define a scale for measuring the life-cycle function supplied by the artifact,

- to record the material and energy provisions during the manufacturing phase,

- to record the material and energy provisions during the operation service,

- to evaluate the material and energy recovery at dismissal, reuse and recycling.

To demonstrate the difference between tangibles (for example a piece of metal) and intangibles (defined by the shape and function, for example a spoon made from the metal), there are some simple provisions:

Provision of tangibles: Extended warranties (supply maintenance) and Temporary allocation of artefacts (leased commodities) 
Provision of intangibles: Temporary use of artefacts (shared commodities) and Dematerialized assignments (function delivery)

KILT is an arbitrarily chosen implementation of TYPUS, we could imagine other realizations as well. However recently the given definition seems to be the best for the author to be used for the requested goals.

The related TYPUS metrics is further discussed in 3.3.

The refunding needs synthetic models, describing the manufacture processes. With earlier models, the delivered quantities (all outputs), Q, are assumed to depend on the contributed financial ( I ) and human ( L ) capitals only.

$Q=f(I, L)$

Simple relations have been employed, such as:

$Q^{o}=\alpha_{o} x I x L$, , or, incrementally:

$\Delta Q^{*}=\beta_{o} x I x L-\beta_{I} x I-\beta_{L} x L$.

Linear input/output models are assumed for instant marginal description of the quantities, or for related increments around an optimal setting. Enhanced models are in use, to include market entry thresholds (Imin and Lmin), or saturations (Imax and Lmax). Similarly, instead of bi-linear dependence, close to steady state, the lack of symmetry could have resort to modulating exponentials.

The know-how ( $\mathrm{K}$ ) innovation and the tangibles ( $\mathrm{T}$ ) bookkeeping have non negligible effects. The modified - and stronger, more closed to the real life relationships became:

$Q=f(K, I, L, T)$

The above given relationships will change to the following:

$Q^{o}=\gamma_{o} x K x I x L x T ;$ or, incrementally:

$\Delta Q^{*}=\delta_{0} x K x I x L x T-\delta_{K} x K-\delta_{I} x I-\delta_{L} x L-\delta_{T} x T$.

Summarizing the different types of capitals and their meaning and some possible components we get:

K: Technical capital - knowledge, technology, know how, etc.- intangibles

I: Financial capital- investment, capital, etc.

L: Human capital- labor, traditional labor, human efforts, welfare charges, etc.

T: Natural capital - tangible resources: material, consumables, ecologic fees, utilities, commodities, etc.

All the contributed technical $\mathrm{K}$, financial $\mathrm{I}$, human $\mathrm{L}$ and natural $\mathrm{T}$ capitals are included, to supply overt account of the knowledge and tangibles effects. Again, 
the tetra-linear dependence assumes to operate nearby equilibrium assets. With optimized choices, the negative appendages accomplish the sensitivity analyses, separately accounting the individual capital contributions. K, I, L and T should have their values, while $\gamma_{\mathrm{o}}, \delta_{\mathrm{o}}, \delta_{\mathrm{K}}, \delta_{\mathrm{I}}, \delta_{\mathrm{L}}$ and $\delta_{\mathrm{T}}$ are appropriate constants - hard to define and determine them.

The new KILT models reliably describe the delivered product quantities, Q. Lacking one contribution (any of the above constants has a value of 0 ), the balance is lame, and the reckoned productivity figures, untruthful or meaningless.

The analyses investigate the piling up invariance is against the resort to nonproprietary technologies, or to off-the-market loans, or to work out-sourcing or productive break-up. These models can be modulated with thresholds and nonlinearities.

The tetra-linear dependence means the equivalence of assets alone, and their synergic cumulated action. The company return is optimal, when the (scaled) factors are balanced; the current scaling expresses in money the four capitals (the comparison of non-homogeneous quantities is meaningless; the output $\mathrm{Q}$ has proper value, with the four inputs homogeneity). The return vanishes or becomes loss, if one contribution disappears. The loss represents the imbalance between constituent (know-how, money, work out-sourcing, bought semi-finished parts, etc.) flows.

In the bi-linear model, the tangibles (utilities or commodities) are attainable without limits. They do not affect the manufacture business; the affordable growth trend is undefined. The changes in technology, knowledge or know-how, simply, rescale the productivity of tangibles, processed along the material flow. The new model presumes the direct concern of the sustainability bounds for energy saving, pollution avoidance, natural goods preservation, and the likes. These bounds require introducing the figure of the resource efficiency. The replacement of material goods is cost to society, with non-negligible environmental impacts, which shall be paid by the benefits holders (and not poured out on third people and future community).

The scaled T-factor measures the "natural" capital use/misuse, with annexed allegations. The technology $\mathrm{K}$ concern has fall-outs at the design, production and sale phases, and, in the manufacture business, is dealt with, for trade fairness, by quality engineering rules. The standard definition of quality, "conformance to specifications", binds the design (technical specifications files) to the delivery approval testing. Anyway, the technology $\mathrm{K}$ comes as primary transformation factor, affecting the manufacture process throughput.

The earlier dependence on the financial I and human L capitals is result, perhaps, of the dialectic opposition between plant owners and labor. The neglect of the tangibles $\mathrm{T}$ factor is surprising, as the manufacture duty has no output, without materials and energy. The addition of the intangibles $\mathrm{K}$ is characteristics of the 
"knowledge" paradigms, and an earlier entry could have been devised from the "new economy" deployment. With the manufacturers' lifecycle responsibility, the explicit role of $\mathrm{K}$ and $\mathrm{T}$ needs to emerge, since the companies' profitability will become critically dependent on how these factors are balanced. The $\mathrm{T}$ vs. $\mathrm{K}$ dialectic opposition is a challenge for tomorrow.

The productivity bookkeeping is merged into global Q assessments, to provide synthetic pictures, with visibility of the four capital assets, as the enterprise's function/facility means. The manufacture shop-floors generate value chains, providing $\mathrm{Q}$ guesses based on the market requests, including the welfarism charges (L factor), according to the enacted rules, and, from now on, the ecologic fees ( $\mathrm{T}$ factor), following, e.g., the in-progress EU directives. With the KILT models, the four manufacture assets easily apply, without modifying many assessed traditional habits.

The classic micro-economic description, basically, leads to the delivery figure $\mathbf{Q}^{\circ}$, maximally concerned by the steady production flow on convenient strategic spans. The flexible automation (with integrated design, in progress, open to time-varying scopes and externalities) leads to $\Delta Q^{*}$, which corresponds to the incremental delivered product quantities on the tactical spans. The steady description states that the changes in technology, finance, labor and supply can freely be performed, without affecting the throughput (products and services). With the "old" bi-linear model; the tangibles (raw materials, utilities or commodities) are attainable without limits, thus, they do not affect the manufacture business, and the affordable development trend is undefined; moreover, the changes in technology, knowledge or know-how simply rescale the productivity of tangibles, processed along the material flow. The new model presumes direct concern of the sustainability bounds for energy saving, pollution avoidance, natural goods preservation, and the likes; these bounds lead to introduce the concept of resource efficiency. The replacement of material goods is a cost to society, with nonnegligible environmental impacts that shall be endorsed by the benefits holders (and not poured out on the community). The fact is dealt with by the scaled Tfactor, with serious implications. The explicit concern of the technology $\mathrm{K}$ has different falls-out at the design, manufacture and sale phases, and, in the manufacturing business, it is dealt with, as for trade fairness, by quality engineering rules.

Actually, "quality" has the standard definition: "conformance to specifications", binding the design (technical specifications files) with the delivery approval testing; quality functions deployment or similar company-wide quality-control setups are later recognized as contrivances to improve efficiency, through zerodefects production. It is updated as "fitness for purposes", with focus on the users' requests. The last definition is ambiguous, unless the quality is measured according to quantitative methods, within the legal metrology frames. This leads to "certified quality", with assessments established by third parties (as compared to sellers and buyers). At the same time, the technology appears as primary 
transformation factor, affecting the throughput of the industrial organizations. The matter can be looked as well, saying that "quality" is technically specified at the design (conformance to specifications) or at the marketing (fitness for purposes) steps, if the reference standards are defined. On this line, the "quality" is widened to include the eco-consistency demands, and the "certified quality" has to be assessed with resort to the TYPUS metrics, or other equivalent enacted standard. Then, quantitative performance functions are stated, to logically connect effectiveness up-grading and capital investments, for detailing impacts and returns of the (four) fixed assets. By that way, quality engineering becomes the meaningful go-between for company-wide information set-ups (measured with formally specified standards). At this point, to assess the value build-up of actually delivered artefacts, the embedded technology has to be accounted for, as primary production factor (not to be merged in the I-factor, as non-distinguishable acquisition, or in the L-factor, as operators' inherent property).

From our point of view equation (3) and (6) are the most interesting. The resulting $\Delta \mathrm{Q}^{*}$ (simply delta $\mathrm{Q}$ ) can be understood and evaluated as the change of delivery, i.e. the change of value of the product between two steps (phases) of the life-cycle. This way LCM has a new meaning, where the value changes can be followed between any steps, which may be consecutive as well. In this type of understanding we do not have to speak about delivery, but about phases of the PLCM process, with defining the value changes. For example the value difference between a painted car body part and the same part unpainted can be estimated by knowing the added quantity of paint $(\mathrm{T})$, the knowledge, how to do it $(\mathrm{K})$, the amount of money to run the painting shop (I), and the human efforts needed (L). We hope to have genuine results - understanding the value chain - if we go ahead this way.

\subsection{Tangibles' Productivity}

The environmental protection is man's right at universal range, with outcomes to safeguard the future generations, not today, represented by efficient political parties or governmental agencies. Then, the democratic consensus or international agreements results deprived of justifications, whether limited to place the interests of the today citizens before. The fair socio-political approach, put forward by the "knowledge" paradigms, compels protecting the generations to come, by compensation ways, such as:

- to create a tax system, which consolidates the wealth corresponding to all withdrawal accomplished from the natural capital, following deposit/refundlike arrangements;

- $\quad$ to forbid natural capital withdrawals that exceed quotas, roughly equal to the reverse logistics recovery, or (hopefully) to the bio-mimicry stimulated generation, in view to keep the original natural capital level, by neutral yield. 
The first way is formal, since, transforming different capitals, the equivalence criteria are, at least, ambiguous. The second, if coherently applied, faces decay limitations, and today runs into the life quality decrease, towards the thrifty society. It is, moreover, possible to merge the two ways, using the "depositrefund" choice as first instance, thereafter keenly researching innovative technologies, out of reverse logistics, which perform active replacing resources and full eco-remediation, to achieve neutral yield of the inherited natural capital.

Many unanswered questions exist (e.g., in terms of comprehensiveness). Still, the EU environmental policy looks aiming at united way. The bookkeeping of the tangibles' decrease and pollutants' increase becomes primary demand, with, as side request, the assessment of the restoring onerousness. Then, the closed-cycle economic/ecologic processes are prerequisite of the manufacture markets to come. The analyses need to be quantitative, to make meaningful comparisons, fulfilling the assessments by recognized standards. The consistent closed-cycle appraisal brings to concepts such as the below new metrics (or similar equivalent standards).

\subsection{The TYPUS Metrics}

TYPUS, tangibles yield per unit service: the measurement plot covers the materials supply chain, from procurement, to recovery, so that every enjoyed product-service has associated eco-figures, assembling the resources consumption and the induced falls-off requiring remediation. The results are expressed in money, resorting to the arbitrariness of establishing stock-replacing prospects. The point is left open, but, it needs to be detailed, to provide quantitative (legal metrology driven) assessment of the "deposit-refund" balance.

The metrics is an effective standard, aiming at the natural capital intensive exploitation. The supply chain lifecycle visibility needs monitoring and recording the joint economic/ecologic issues, giving quantitative assessment of all input/output materials and energy flows. The new tax system has to operate on these data, establishing consumption rates at the input, and pollution rates at the output, to obtain the 'wealth equivalent' of the overall impact (as for the first mentioned way).

When a metrics, such as TYPUS, is adopted, conservative behaviors are quickly fostered. The ecologic bent of the taxing systems becomes enabling spur, to turn the "knowledge" paradigms towards environmental friendly goals. The TYPUS, tangibles yield per unit service, metrics can, of course, take other forms. The objective is to look after capital conservative arrangements, notably, as for the natural assets. In different words, the objective is saving the wealth (the capital), and to tax the consumption (the imbalance of the natural resources).

Today, the eco-fee evaluation is quite obscure, due to political biases. It leads to taxing schemas, which draw from the whole capital, more than in proportion to the 
actual impact (net consumption combined to pollution). The eco-protection, switched into the individual consumers' business, is starting point, to look for higher efficiency, over the whole supply chain, from provisioning to recovery, using all-comprehensive effectiveness criteria, singly dealing with each capital asset (tangibles' productivity included).

The natural capital bookkeeping will become standard routine of the knowledge society. Today, the economic accounting to detect unlawful habits (crime, repression, etc.) is obvious practice, affecting personal liability. Similarly, the thought-out ecological accounting needs to develop into steady rehearsal, in view to charge the actual consumers (to the advantage of third people and future generations). With the «knowledge» paradigms, the tax regulation restructuring is required, because the socio-political aspects management becomes important contribution to effectiveness. The biggest question is how to distinguish the community's, from the individual's duties.

The solution offered by the capitalism (in western world style) is noteworthy issue. The personal liability is consequence of the independent freedom to organize the exclusive fortune. In the place of shared figures, the individual accountability offers rewards through competition. The averaged taxation of input/output materials and energy flows is simple, being linked to nominal parameters, limiting the control to out-of-all quantities (provisioning and landfilling). This is local communities business, with visible fees refund, depending on the efficiency of averaged balances. The ecological accounting through the TYPUS metrics is more tangled affair, needing to address each single supply chain. The competition shifts at that level, and the lifecycle manufacturers' responsibility is viable bookkeeping charge (under registered overseeing). At least, this is fair practice, deserving attention.

\section{Conclusions and Further Plans}

Our real goal is to give some means and tools to calculate different values which correspond to different phases of the life-cycle (LC) of a product. We specially emphasize re-use and re-cycling as important LC phases, due to approaching water-, energy- and raw material-shortages.

On product we mean anything what is used by simple users (a car, a cup, a bike, or a part of them, etc.), or what are used by dedicated users to produce or manage other products (a machine tool, a robot, a house, a test environment, etc.), or which are used to manage everything else (a firm, a factory, a ministry, etc.). We differentiate between simple products and extended products (as traditional and extended enterprise) and between tangible and intangible parts (aspects) and service is taken into account as a product, too.

The TYPUS metrics and the KILT model say, that the delivery of a firm can be calculated with a seemingly simple multiplication of 4 main factors, as Knowledge (innovation) /K/, Investment /I/, Labor (financial and human capital)/L/ and 
Tangibles (materials)/T/ - modified by appropriate constants and additional factors. Delivery means the goal-products and all side effects (water consumption, $\mathrm{CO}_{2}$ disclosure, etc.) together.

Based on these calculations real data can be given on all effects, side effects and $2^{\text {nd }}, 3^{\text {rd }}$ order side effects of products and productions, e.g. $\mathrm{CO}_{2}$ emission can be properly evaluated. As the first practical results we hope to get useful calculations using equation (6) - or a mutation of it - for getting delta $\mathrm{Q}$, what we consider as value change between any two phases of the LCM of any product.

We know that the above given forms cannot yet be used for economically useful calculations, they contain only several ideas and qualitative relationships to go on a right way. We plan to find proper relationships to use our ideas and formulae for real world situations to assist not only designers and engineers in their work, but politicians and other decision makers as well. These studies and their resulting calculations, values and suggestions how to proceed will be in a following study.

\section{References}

[1] Michelini, R. C., Kovács, G. L.: Integrated Design for Sustainability: Intelligence for Eco-Consistent Products and Services, in: EBS REVIEW, ISSN 1406-0264, Innovation, Knowledge, Marketing and Ethics, Winter 2002/2003, pp. 81-94

[2] Rinaldo R. Michelini: Knowledge Enterpreneurship and Sustainable Growth, (book, 325 pages), NOVA Science Publ., 2008

[3] Rinaldo R. Michelini: Knowledge Society Engineering, A Sustainable Growth Pledge, (book, 350 pages), NOVA Science Publ., 2010

[4] Gale Cengage: American Decades, C2000. Published/Released: December 2000, ISBN 13: 9780787650766, ISBN 10: 0787650765, DDC: 973.91, Product number: 172108, Shipping Weight: 49.00 lbs , Price: US \$1495.00

[5] Richard Schmalensee, Thomas M. Stoker, and Ruth A. Judson: World Energy Consumption and Carbon Dioxide Emissions: 1950 Ñ 2050, MIT, 1995 study, pp. 1-40

[6] John c. Dernbach, editor: Stumbling Towards Sustainability, book, Published in July 2002 by the Environmental Law Institute, Washington D.C., ISBN: 1-58576-036-6, pp. 1-968 